\title{
The Peritraumatic Behavior Questionnaire: development and initial validation of a new measure for combat-related peritraumatic reactions
}

Agorastos Agorastos 1,2, William P Nash ${ }^{3}$, Sarah Nunnink ${ }^{1,3,4}$, Kate A Yurgil $^{4}$, Abigail Goldsmith ${ }^{3,4}$, Brett T Litz ${ }^{5,6}$, Heather Johnson ${ }^{4}$, James B Lohr ${ }^{1,3,4}$ and Dewleen G Baker $r^{1,3,4,7^{*}}$

\begin{abstract}
Background: Posttraumatic stress disorder (PTSD) is one of the most commonly observed stress-related conditions following combat exposure and its effective prevention is a high health-care priority. Reports of peritraumatic reactions have been shown to be highly associated with PTSD among combat exposed service members. However, existing instruments measuring peritraumatic symptoms were not specifically developed to assess combat-related peritraumatic stress and each demonstrates a different peritraumatic focus. We therefore developed the Peritraumatic Behavior Questionnaire (PBQ), a new military-specific rating scale focused upon the wide range of symptoms suggestive of combat-related peritraumatic distress in actively deployed Service Members. This study describes the development of the PBQ and reports on the psychometric properties of its self-rated version (PBQ-SR).

Methods: 688 Marine infantry service members were retrospectively assessed by the PBQ-SR within the scope of the Marine Resiliency Study after their deployment to war zone. Participants have been additionally assessed by a variety of questionnaires, as well as clinical interviews both pre and post-deployment.

Results: The PBQ-SR demonstrated satisfactory internal consistency, convergent and discriminant validity, as well as high correlation with trait dissociation prior to deployment. Component analysis suggested a latent bi-dimensional structure separating a peritraumatic emotional distress and physical awareness factor. The PBQ-SR total score showed high correlation to general anxiety, depression, poorer general health and posttraumatic symptoms after deployment and remained a significant predictor of PTSD severity, after controlling for those measures. The suggested screening cut-off score of 12 points demonstrated satisfactory predictive power.

Conclusions: This study confirms the ability of the PBQ-SR to unify the underlying peritraumatic symptom dimensions and reliably assess combat-related peritraumatic reaction as a general construct. The PBQ-SR demonstrated promise as a potential standard screening measure in military clinical practice, while It's predictive power should be established in prospective studies.
\end{abstract}

Keywords: Peritraumatic behavior questionnaire, Peritraumatic dissociation, Peritraumatic reaction, Posttraumatic stress disorder (PTSD), Stress, Psychometric properties, Validity, Reliability, Screening, Assessment

\footnotetext{
* Correspondence: dgbaker@ucsd.edu

'Veterans Affairs Center of Excellence for Stress and Mental Health, VA San Diego, CA, USA

${ }^{3}$ Department of Psychiatry, University of California, San Diego, CA, USA

Full list of author information is available at the end of the article
} 


\section{Background}

Posttraumatic stress disorder (PTSD) is one of the most common stress-related conditions in active duty Service Members after combat exposure [1-3]. Early at-risk detection and prevention of the development of PTSD could therefore lead to substantial benefits concerning the potential personal, social, and economic consequences of this disorder in military populations [4-6]. Although prior literature has identified pre-existing and post-hoc risk factors for PTSD, limitations in the predictive value of these factors have recently prompted particular interest in the immediate peritraumatic response after trauma exposure as a fairly robust predictor of PTSD development.

Peritraumatic stress reactions refer to the different stress-associated behavioral, emotional, cognitive, and physiological symptoms during and immediately following a traumatic event (e.g., fear of dying, fear of losing emotional control, tachycardia, sweating, shaking, dizziness, dissociative symptoms, reduction of awareness, etc.). These reactions have demonstrated a strong and consistent association with the subsequent development of posttraumatic stress symptoms [7-18]. The degree of the peritraumatic adrenergic hyperactivation following a stressful or traumatic event is related to different patterns of physiological response [19], subjective experience of injury and trauma-related fears [11,20], resilience and coping mechanisms [21], poor military training outcomes [22,23], as well as symptomatic outcomes in trauma sequelae $[21,24]$. Pathophysiological pathways suggested for increasing the risk for PTSD include enhanced fear conditioning [25], behavioral avoidance coping [26], memory processing disruption [27-30], and over-consolidation of traumatic memories [31,32]. A prolonged continuation of the biological and behavioral responses following acute traumatic stress may lead to greater pairing of the traumatic memory with distress, initiating a cascade of secondary biological alterations with long-term adverse consequences including interference with fear extinction learning and retention [33-36]. Peritraumatic stress is, thus, a salient pre-clinical indicator of risk and could provide sufficient evidence to warrant evaluation, the provision of stress first aid, and, if necessary, sustained formal mental health intervention to promote healing and recovery [37-42].

Yet, the valid assessment of relevant behavioral, emotional, cognitive, and physiological information is the greatest challenge in combat-related, mental health research. Although instruments measuring peritraumatic symptoms exist, they were not specifically developed to assess combat-related peritraumatic reactions. In addition, the two most widely used peritraumatic scales each demonstrate different peritraumatic foci. The Peritraumatic Dissociative Experiences Questionnaire (PDEQ) mainly assesses dissociative symptoms and physical reactions, while the Peritraumatic Distress Inventory (PDI) primarily targets emotional/cognitive peritraumatic aspects [43-47]. Thus, when used independently, these scales may insufficiently capture the wide range of possible symptoms or reactions in the immediate aftermath of a combat-related trauma.

To redress this problem, we developed the Peritraumatic Behavior Questionnaire (PBQ). The goal was to generate a new, military-specific rating scale able to unify the underlying peritraumatic symptom dimensions and reliably assess combat-related peritraumatic reaction as a general construct in actively deployed Service Members. The goal of this primary study lies in the demonstration of satisfactory psychometric properties of the subjective PBQ version (PBQ - Self Report, PBQ-SR).

\section{Methods}

\section{Subjects}

All subjects enrolled were consenting active duty male Marines recruited from infantry battalions of the 1st Marine Division stationed at Marine Corps Air-Ground Combat Center, 29 Palms, or Camp Pendleton, in southern California. Because the MRS study targeted only ground combat units, no women were included in the study. Ethnic distribution was included in similar proportion to the representation in the Marine Corps [48] (cf. Table 1, legend). There were no other exclusion criteria. 706 deploying male Marines signed informed consent prior to deployment and were included in the study. Of all deployed participants, 688 Marines (mean age $22.1 \pm 3.4$ years) participated in post-deployment assessments, returned valid questionnaires and were included in our analysis (cf. Table 1). Of those, 404 Marine subjects reported no history of prior combat deployments.

\section{Development of the peritraumatic behavior questionnaire} The goal was to develop a questionnaire that is easy to administer and score due to its simple rating and scoring instructions and clearly specified areas of evaluation. To develop the content for the Peritraumatic Behavior Questionnaire (PBQ) for use in a war zone, a panel of subject matter experts generated an initial pool of items and helped select the final set of items, emphasizing content validity $[49,50]$. The expert panel was formed by established clinical mental health professionals, with experience treating in-theater and post-deployment, combat-related, acute and posttraumatic stress symptoms, as well as research professionals with a focus in PTSD. The PBQ-SR was developed using the expert consensus method in four steps (Step 1: Item pool generation; Step 2: Item pool screening; Step 3: Items' adjustment; Step 4: Final review) [51]. 
Table 1 Means of psychometric scores assessed by different instruments in the sample

\begin{tabular}{|c|c|c|c|c|c|c|}
\hline \multirow[t]{2}{*}{ Total scores } & \multicolumn{2}{|c|}{$\begin{array}{l}\text { Whole sample } e^{a, b} \\
\left(n=688^{+}\right)\end{array}$} & \multicolumn{2}{|c|}{$\begin{array}{l}\text { No prior deployment } \\
(n=404)\end{array}$} & \multicolumn{2}{|c|}{$\begin{array}{c}\text { No prior deployment }{ }^{\mathrm{b}} \text { and } \mathrm{PBQ}>12 \\
(\mathrm{n}=70)\end{array}$} \\
\hline & Mean & SD & Mean & SD & Mean & SD \\
\hline BAI - Post-deployment & 4.2 & 7.0 & 4.1 & 7.0 & 9.9 & 11.1 \\
\hline BDI - Post-deployment & 4.7 & 6.8 & 4.6 & 7.0 & 11.4 & 11.3 \\
\hline CAPS - Baseline & 7.3 & 12.7 & 7.2 & 12.7 & 13.8 & 18.0 \\
\hline CAPS - Post-deployment & 10.6 & 16.0 & 9.7 & 15.4 & 22.7 & 25.4 \\
\hline CAPS - Change & 3.1 & 16.9 & 2.5 & 17.2 & 8.7 & 26.5 \\
\hline DES - Baseline & 9.2 & 10.8 & 10.0 & 11.6 & 16.2 & 15.7 \\
\hline PCL - Baseline & 22.7 & 8.7 & 22.9 & 8.9 & 27.5 & 10.5 \\
\hline PCL - Post-deployment & 23.0 & 9.1 & 22.5 & 8.4 & 30.5 & 13.9 \\
\hline PCL - Change & .3 & 9.8 & -.4 & 9.7 & 3.0 & 13.6 \\
\hline PDEQ - Post-deployment & 16.0 & 7.2 & 15.9 & 7.1 & 21.4 & 9.6 \\
\hline PBQ - Total Score & 5.1 & 7.1 & 5.5 & 7.3 & 19.0 & 6.1 \\
\hline SF12 Physical Score - Post-deployment & 53.6 & 6.54 & 54.0 & 6.3 & 52.6 & 8.4 \\
\hline SF12 Mental Score - Post-deployment & 51.2 & 8.7 & 51.1 & 8.7 & 45.6 & 11.2 \\
\hline PANAS-Positive Post-deployment & 33.9 & 9.0 & 34.1 & 9.1 & 34.5 & 9.4 \\
\hline PANAS-Negative Post-deployment & 17.5 & 6.5 & 17.6 & 6.7 & 22.5 & 7.4 \\
\hline WHODAS Post-deployment & 13.9 & 4.2 & 13.9 & 4.4 & 17.0 & 7.2 \\
\hline
\end{tabular}

Total scores of psychometric scores are reported as mean values \pm SD. Measures were assessed either before (Baseline) or after deployment (Post-deployment). Changes indicate differences in the scores between pre and post-deployment. BAI: Beck's Anxiety Index; BDI: Beck's Depression Inventory-II; CAPS: Clinician Administered PTSD Scale; DES: Dissociative Experiences Scale-II; PANAS: Positive Affect Negative Affect Schedule; PDEQ: Peritraumatic Dissociative Experiences Questionnaire - Self Report; PCL: PTSD Checklist; SF-12: Short Form 12, Version 2; WHODAS: World Health Organization Disability Assessment Schedule II.

${ }^{a}$ Demographics of whole sample in percentage (percentages under 1.0\% are not reported).: Education (Some High School: 1.9\%; GED: 1.5\%; High School Diploma: 60.2\%; Some College: 30.6\%; Associates Degree: 2.5\%; 4-year College Degree: 3.1\%), Ethnicity (Not Hispanic or Latino: 74.6\%; Mexican: 14.2\%; Puerto Rican: 2.8\%; South or Central American: 3.2\%; Other Spanish culture or origin: 5.2\%), Race (Black or African American: 4.9\%; American Indian or Alaskan Native: 1.5\%; Asian: 2.7\%; Native Hawaiian or Pacific Islander: $1.0 \%$; White: $83.7 \%$; More than one: $7.2 \%)$.

${ }^{\mathrm{b}}$ There were no statistical significant differences in demographics between the different groups (data not shown).

${ }^{\dagger}$ Drop-out reasons included transfer, hospitalization, relocation or discharge of Service Members.

In step 1, a large item pool with different questions assessing peritraumatic reactions was generated. Constructs considered for inclusion were frequently observed peritraumatic symptoms seen in the battlefield of operations. Items were collected through summarizing clinical expertise derived from prior battle-field experience with traumatized Service Members, clinical notes and prior patients' comments, a comprehensive literature review focused upon peritraumatic symptoms using a standard database search, and well established peritraumatic and dissociation questionnaires found to correlate with PTSD development, trauma history or symptom severity (e.g. Peritraumatic Distress Inventory - PDI; Peritraumatic Dissociative Experiences Questionnaire - PDEQ; Somatoform Dissociation Questionnaire - SDQ-20, Clinician Administered Dissociative Symptoms Scale - CADSS) [44,45,47,52-55]. In step 2, the item pool was screened to determine: (a) the questions' applicability and relevance to military war zone experiences and culture and (b) the feasibility of objectively observing described symptoms, an attribute additionally rated by a focus group of Navy corpsmen previously deployed with Marine combat units. Peritraumatic reactions in battle are representative for extraordinary stress challenges for Service Members, who are faced with pervasive loss, life threat, extreme physical discomfort and moral conflicts, witnessing death and overcoming fear [56]. However during combat, the primary importance of these reactions lies in potential interference with maintenance of operational resilience, including mission effectiveness and optimal performance [57]. Thus as those aspects of peritraumatic reactions are already to deployed Service Members and salient to combat operations, special attention has been given to including such items in our questionnaire. Missing pool items addressing possible emotional changes or loss of control sometimes experienced in the aftermath of trauma or loss were identified and consequently also included into the item pool (i.e. items such as "acting inappropriately giddy or silly"; "uncontrollable laughing, crying, or screaming"; and "not feeling normally remorseful"). On the contrary, several questions reflecting ubiquitous experiences in theater (e.g., "I was afraid for my safety") were excluded from the item pool. Step 3 included slight language modifications of the collected questions in order to reflect military terminology and to qualify for use in military operational settings. In the final step, the selected items were reviewed 
again by the expert's panel in order to ensure that all different battle-field related stress symptoms were adequately represented in the draft.

A total of 15 potential scale items were then selected from the remaining item pool (cf. Additional file 1). The final questionnaire items were refined and assembled into a 5-point-Likert scale structure, ranging from "Not at All True" to "Extremely True" (scored 0-4), to promote the comparability of our results to prior studies using existing questionnaires. Finally, the self-report version (PBQ-SR) was created by merely using first-person pronouns such as "I" and "my". All questions refer to symptoms during and/or immediately after the most stressful event experienced during the last deployment. It was further specified in the measure's instructions that these reactions must have been unusual for the individual and not within their typical range of thoughts, emotions or behavior. The PBQ-SR can be completed within 5 min. The 15 individual items were summed to compute a single summary score. Higher scores indicate higher levels of peritraumatic symptoms.

\section{Methods}

This study used data collected within the scope of the "Validation of the Peritraumatic Behavior Questionnaire" study, approved by the institutional review boards of the University of California San Diego, the VA San Diego Research Service (VA R\&D and UCSD IRB approval \#090563), the Brooke Army Medical Center and CENTCOM. This is a pilot study linked to the "Marine Resiliency Study" (MRS), a larger prospective investigation of active duty Marines approved by the institutional review boards of the University of California San Diego, VA San Diego Research Service, and Naval Health Research Center (VA R\&D and UCSD IRB approval \#070533) [48].

Informed consent for all deploying MRS Marines volunteering for this study was obtained prior to deployment. The PBQ-SR was administered to Marines at post-deployment assessment, along with other MRS study questionnaires, as part of the standard test battery for the MRS study. Exact post-deployment evaluation time periods varied between 8 and 12 weeks postdeployment depending on pre-scheduled assessment time points. Each platoon of each company were available for $1 / 2$ day for collection of data, including paperpencil questionnaires (approx. $1 \frac{1}{2} \mathrm{hrs}$ ). Two to four study staff members were specifically designated for monitoring of participants during questionnaires, as well as being present to answer questions, but were not constantly in the room where single participants filled out self-report measures. Survey response confidentiality was maintained at any time by providing spacing of at least 5 feet between chairs/desks where self-report questionnaires were completed by participants. Assessments were mainly conducted in Marine training spaces on a Marine Corps base, except for Marines not available to be tested with their units if discharged after deployment, transferred to a different unit or hospitalized. Those Marines were assessed at the VA San Diego Medical Center or at other locations.

\section{Measures}

All MRS participants completed the following questionnaire prior to deployment only:

- The Dissociative Experiences Scale-II (DES): The DES is a 28-item, 11-point-Likert-scaled, self-report questionnaire assessing dissociative symptomatology during the past month. The DES has reported satisfactory psychometric properties, while higher scores indicate higher dissociative traits $[58,59]$.

Participants also completed the following instruments both pre- and post-deployment:

- The PTSD Checklist (PCL): The PCL, a 17-item, 5-point-Likert-scaled, self-report questionnaire assessing PTSD symptom severity. The PCL has repeatedly demonstrated good psychometric qualities with higher scores indicating higher PTSD symptom severity $[60,61]$. In our study the PCL was used with respect to a specific traumatic event.

- The Clinician Administered PTSD Scale (CAPS): The CAPS was administered by trained clinicians in a face-to-face interview with MRS participants both pre- and post-deployment. The CAPS is a structured diagnostic interview that assesses the core and associated symptoms of PTSD and is considered the gold standard diagnostic manual for assessing PTSD in clinical research [62-64]. While several scoring rules and cut-off scores have been suggested, higher scores indicate higher symptom severity [64].

Finally, in addition to the PBQ-SR, the following questionnaires were administered after deployment only:

- Peritraumatic Dissociative Experiences Questionnaire Self Report (PDEQ): The PDEQ is a 10-item, 5-point-Likert-scaled, self-report questionnaire assessing peritraumatic dissociation. The PDEQ has well-established psychometric properties, with higher total scores indicating increased peritraumatic dissociation $[43,54]$ thus served as the reference standard in the evaluation of the PBQ-SR.

- Positive Affect Negative Affect Schedule (PANAS): The PANAS consists of two 10-item self-report scales designed to provide independent measures of positive (PANAS-P) and negative affectivity (PANAS-N). 
Each item is rated on a five-point-Likert scale, while low scores reflect the absence of the reported feelings $[65,66]$.

- Beck Depression Inventory-II (BDI): The BDI is a 21item, four-point-Likert-scaled, self-rating scale designed to measure emotional, cognitive, behavioural and somatic symptoms of depression over the previous two weeks and has become one of the most widely accepted instruments for detecting depression in normal populations $[67,68]$.

- Beck Anxiety Index (BAI): The BAI is an established 21-item, four-point-Likert-scaled, self-report instrument assessing severity of anxiety symptoms during the past week [69].

- Short Form 12, Version 2 (SF-12): The SF-12 is a widely used and repeatedly validated, 12-item, 5 and 3-point-Likert-scaled, self-report questionnaire assessing health-related quality of life. Sub-scores are divided according to physical and mental health items. The SF-12 was developed as a more concise alternative to the original SF-36 and has been shown to mirror closely the physical and mental components of the original form, such as pain, general health, physical functioning, social functioning, vitality, etc. [70].

- World Health Organization Disability Assessment Schedule-II (WHODAS), Short Version: Developed from the original 36-item version, the WHODAS-II, Short Version is a 17 -item, self-report generic healthstatus instrument assessing functioning in the last 30 days in six domains: communication, mobility, selfcare, interpersonal, life activities, and participation [71]. The first 12 items are 5-point Likert-scale questions that assess areas of functioning while 5 additional items pertain to overall health, frequency of functional impairments, and interference caused by impairments. Only the 12 core items are aggregated into a total score.

\section{Statistical analysis}

The main objective was the assessment of the major psychometric properties of the PBQ-SR. Internal consistency was assessed using corrected item-total correlations and Cronbach's alpha coefficients. Construct validity was investigated by assessing the convergent and discriminant validity of the measure with respect to previously established measures. PBQ-SR internal consistency, as well as convergent and discriminant reliability were explored using the entire sample $(\mathrm{N}=688)$. Concurrent validity of the PBQ-SR was assessed in order to explore its correlation to related measure scores assessed in our samples after deployment. In order to avoid bias of combat-related stresses or traumas associated with prior deployments, we excluded previously deployed Marines from this analysis.
Concurrent validity correlations and cut-off scores were explored and calculated only in the sub-sample without any history of prior deployment $(\mathrm{N}=404)$. A CAPS screening cut-off score of $\geq 45$ was used to dichotomize the population, as suggested in the literature [64]. Changes in measures were computed as differences in total scores between pre- and post-deployment. Preliminary analyses were performed to ensure no violation of normality, linearity and homoscedasticity. Descriptive statistics are given in mean and standard deviation (SD) for ordinal scaled variables. Correlations are reported by the Pearson product-moment correlation coefficient and group differences were calculated by an independent-samples $t$-test. All tests of significance were 2-tailed, and p-values $<.05$ were considered significant. Statistical analyses were conducted using the Statistical Package for Social Sciences Version 20 (SPSS Inc., Chicago, IL).

\section{Results}

\section{Clinical characteristics}

The means and SD of all instruments assessed are presented in Table 1.

\section{Factor analysis}

The 15 items of the PBQ-SR were subjected to principal components analysis (PCA) with direct oblimin rotation to investigate the underlying structure of the questionnaire. Prior to performing PCA, the suitability of data was confirmed (Kaiser-Meyer-Olkin value: .893; Barlett's test of sphericity: $\mathrm{p}<.001$ ). PCA suggested a two-factor solution with only two components exceeding an eigenvalue $>1$, explaining $38.1 \%$ and $12.4 \%$ of the variance respectively. An inspection of the screeplot revealed a clear break after the second component. The two-factor solution explained a total of $50.5 \%$ of the variance. The correlation between the two factors was $r=.39$. Aligned with the two-factor solution, we divided the two subscales of the PBQ-SR, entitled Emotional Distress Subscale (EDS) and Physical Awareness Subscale (PAS), according to the different item content of the components included. The EDS included emotional, perspective and coping items, while the PAS reflected awareness, dissociative and physical symptom items.

\section{Reliability}

The PBQ-SR total score demonstrated good internal consistency, with a reported Cronbach's alpha coefficient of .86. The inter-item correlation matrix revealed only positive values (mean .331), indicating proper scoring and that all items measured the same underlying attribute. The corrected item-total correlations varied between .406 and .644 for all items, while deletion of single items did not significantly change the alpha value, suggesting that the sum of the 15 items is acceptable to 
Table 2 Principal component analysis and convergent, discriminate and concurrent validity of the PBQ-SR

\begin{tabular}{|c|c|c|c|c|c|c|c|c|c|c|c|c|}
\hline \multirow[t]{3}{*}{ Item } & \multirow{3}{*}{$\begin{array}{l}\text { Item-total } \\
\text { correlation }\end{array}$} & \multirow[t]{3}{*}{$a$ if Item deleted } & \multirow[t]{3}{*}{ Mean } & \multirow[t]{3}{*}{ SD } & \multirow{2}{*}{\multicolumn{2}{|c|}{$\begin{array}{c}\text { Pattern coefficients } \\
\text { Component }\end{array}$}} & \multirow{2}{*}{\multicolumn{2}{|c|}{$\begin{array}{c}\text { Structure coefficients } \\
\text { Component }\end{array}$}} & \multirow[t]{3}{*}{ Communalities } & \multirow[t]{3}{*}{ PDEQ } & \multirow[t]{3}{*}{ PANAS-P } & \multirow[t]{3}{*}{ CAPS } \\
\hline & & & & & & & & & & & & \\
\hline & & & & & 1 & 2 & 1 & 2 & & & & \\
\hline PBQ 1 & .610 & .851 & .57 & .953 & .259 & .550 & .473 & .650 & .480 & $.347^{* *}$ & -.038 & $.415^{* *}$ \\
\hline PBQ 2 & .406 & .866 & .71 & 1.120 & -.214 & .749 & .078 & .666 & .482 & $.144^{* *}$ & .052 & $.217^{* *}$ \\
\hline PBQ 3 & .516 & .856 & .30 & .775 & .021 & .669 & .281 & .677 & .459 & $.194^{* *}$ & -.005 & $.197^{* *}$ \\
\hline PBQ 4 & .586 & .853 & .58 & 1.085 & -.095 & .832 & .228 & .795 & .640 & $.232^{* *}$ & .032 & $.286^{* *}$ \\
\hline PBQ 5 & .553 & .857 & .74 & 1.214 & .061 & .667 & .321 & .691 & .481 & $.230^{* *}$ & .007 & $.287^{* *}$ \\
\hline PBQ 6 & .481 & .858 & .21 & .631 & .132 & .529 & .338 & .581 & .352 & $.215^{* *}$ & .027 & $.264^{* *}$ \\
\hline PBQ 7 & .546 & .857 & .15 & .526 & .410 & .363 & .551 & .522 & .415 & $.262^{* *}$ & -.009 & $.230^{* *}$ \\
\hline PBQ 8 & .628 & .853 & .21 & .593 & .582 & .294 & .696 & .520 & .558 & $.286^{* *}$ & -.046 & $.269^{* *}$ \\
\hline PBQ 9 & .644 & .852 & .21 & .647 & .703 & .196 & .779 & .470 & .640 & $.274^{* *}$ & .014 & $.251^{* *}$ \\
\hline PBQ 10 & .424 & .861 & .10 & .466 & .785 & -.143 & .729 & .162 & .549 & $.192^{* *}$ & .015 & $.120^{*}$ \\
\hline PBQ 11 & .445 & .861 & .13 & .477 & .785 & -.113 & .741 & .192 & .560 & $.323^{* *}$ & .034 & $.201^{* *}$ \\
\hline PBQ 12 & .534 & .857 & .19 & .589 & .581 & .184 & .653 & .410 & .455 & $.309^{* *}$ & .028 & $.228^{* *}$ \\
\hline PBQ 13 & .453 & .860 & .15 & .582 & .813 & -.124 & .765 & .192 & .598 & $.280^{* *}$ & -.062 & $.249^{* *}$ \\
\hline PBQ 14 & .548 & .855 & .45 & .948 & .208 & .520 & .410 & .600 & .397 & $.258^{* *}$ & -.003 & $.275^{* *}$ \\
\hline PBQ 15 & .591 & .852 & .39 & .889 & .591 & .228 & .680 & .458 & .507 & $.399^{* *}$ & -.002 & $.364^{* *}$ \\
\hline PBQ Total & & & 5.10 & 7.08 & & & & & & $.422^{* *}$ & .008 & $.436^{* *}$ \\
\hline EDS & & & & & & & & & & $.391^{* *}$ & -.012 & $.309^{* *}$ \\
\hline PAS & & & & & & & & & & $.325^{* *}$ & .017 & $.397^{* *}$ \\
\hline
\end{tabular}

Pattern and structure matrix of PCA with Oblimin rotation of two factor solution of PBQ-SR items and convergent, discriminate and concurrent validity of all items and total scores in the whole sample ( $\mathrm{n}=687$ ). Correlations are given by the Pearson's $r$. PBQ: Peritraumatic Behavior Questionnaire; EDS: Emotional Distress Subscale; PAS: Physical Awareness Subscale; CAPS: Clinician Administered PTSD Scale; DES: Dissociative Experiences Scale-II; PANAS-P: Positive Affect Negative Affect Schedule - Positive Affect Scale; PDEQ: Peritraumatic Dissociative Experiences Questionnaire - Self Report:.

"Statistical trend: $05<\mathrm{p}<0.1$.

${ }^{*} \mathrm{p}<.05$.

** $\mathrm{p}<.001$.

${ }^{+}$including only participants without prior deployment. 
be used as a measure of peritraumatic reactions in battle-related trauma (cf. Table 2). The psychometric properties of both subscales were computed separately. The EDS and the PAS both displayed a good internal consistency (Cronbach's alpha $=0.80$ and .85 respectively).

\section{Construct validity}

Convergent validity was assessed using a Pearson product-moment correlation test to the PDEQ total score. We observed a robust statistically significant positive correlation between the total scores of the two measures $(\mathrm{r}=.422, \mathrm{p}<.001, \mathrm{n}=667)$, as well as between each of the PBQ-SR items and PDEQ total score (cf. Table 2). Discriminant validity was examined by exploring the association between PBQ-SR total score and the divergent and theoretically unrelated constructs of PANAS-P scale. The PBQ-SR did not correlate with PANAS-P total score at all $(\mathrm{r}=.008, \mathrm{p}=.846, \mathrm{n}=661)$. In the sample without prior deployment, PBQ-SR even showed a slight negative discriminant correlation to the PANAS-P, similarly to the PDEQ, confirming that the two scales are both equally unrelated to a conceptually different measure such the PANAS-P Scale. The EDS and the PAS both also displayed a satisfactory convergent and discriminant validity (cf. Table 2).

\section{Concurrent validity}

Concurrent validity was measured by exploring the relation of the PBQ-SR total score to several scales assessing general anxiety, depression, negative affect, lower general health and posttraumatic symptoms after deployment and their changes over time, showing significant correlations (cf. Table 3). In addition, the PBQ-SR showed a significant positive correlation to the DES total score $(r=.256$; $\mathrm{p}<.001, \mathrm{n}=401$; cf. Table 3 ). The same correlations of these measures to PDEQ were also computed and presented in Table 3. Controlling for CAPS and PCL baseline scores had no significant effect on our results. The EDS and the PAS both displayed a significant concurrent validity correlations to other measures (cf. Table 3).

\section{Multivariate analyses}

Hierarchical multiple regression models were used to evaluate associations between PBQ-SR and PTSD symptomology while controlling for co-morbid anxiety and depressive symptoms, general health status, personality and emotional trait factors in terms of criterion validity. PTSD symptoms were indexed by CAPS and PCL total scores, however due to their high collinearity, CAPS and PCL total scores were entered as dependent variables in separate regression models. Preliminary analyses were conducted to ensure no violation of normality, linearity, multicollinearity and homoscedasticity. BDI, BAI, WHODAS, DES and PANAS-N total scores were entered as
Table 3 Correlations of peritraumatic instruments to measures assessed post-deployment in participants without prior deployment $(n=404)$

\begin{tabular}{lllll}
\hline Scales & PDEQ & PBQ-SR & EDS & PAS \\
\hline BAI & $.348^{* *}$ & $.478^{* *}$ & $.442^{* *}$ & $.385^{* *}$ \\
BDI & $.381^{* *}$ & $.531^{* *}$ & $.402^{* *}$ & $.487^{* *}$ \\
DES & $.220^{* *}$ & $.256^{* *}$ & $.188^{* *}$ & $.238^{* *}$ \\
CAPS & $.457^{* *}$ & $.400^{* *}$ & $.305^{* *}$ & $.361^{* *}$ \\
CAPS - Change & $.185^{* *}$ & $.201^{* *}$ & $.200^{* *}$ & $.148^{*}$ \\
PCL & $.485^{* *}$ & $.488^{* *}$ & $.395^{* *}$ & $.423^{* *}$ \\
PCL - Change & $.103^{*}$ & $.209^{* *}$ & $.227^{* *}$ & $.137^{*}$ \\
SF-12 Physical & -.037 & $-.086^{*}$ & $-.143^{*}$ & -.031 \\
SF-12 mental & $-.308^{* *}$ & $-.336^{* *}$ & $-.328^{* *}$ & $-.261^{* *}$ \\
WHODAS & $.266^{* *}$ & $.372^{* *}$ & $.384^{* *}$ & $.276^{* *}$ \\
PANAS - Negative & $.278^{* *}$ & $.384^{* *}$ & $.286^{* *}$ & $.358^{* *}$ \\
PANAS - Positive & -.052 & -.011 & -.010 & -.020 \\
\hline Correations a given by & &
\end{tabular}

Correlations are given by the Pearson's $r$. PBQ: Peritraumatic Behavior Questionnaire; EDS: Emotional Distress Subscale; PAS: Physical Awareness Subscale. BAI: Beck's Anxiety Index; BDI: Beck's Depression Inventory-II; CAPS: Clinician Administered PTSD Scale; DES: Dissociative Experiences Scale-Il; PANAS: Positive Affect Negative Affect Schedule; PDEQ: Peritraumatic Dissociative Experiences Questionnaire - Self Report; PCL: PTSD Checklist; SF12: Short Form 12, Version 2; WHODAS: World Health Organization Disability Assessment Schedule II. Change indicates differences in the scores between pre and post-deployment.

\# Statistical trend: $.05<\mathrm{p}<0.1$.

$* \mathrm{p}<.05$.

${ }^{* *} \mathrm{p}<.001$

independent variables at step 1 and PBQ-SR in step 2. The final models were statistically significant and explained a total variance of $34.7 \%\left(\mathrm{~F}_{(6,389)}=34.4, \mathrm{p}<.001\right)$ and $47 \%\left(\mathrm{~F}_{(6,389)}=57.6, \mathrm{p}<.001\right)$ for CAPS and PCL scores, respectively. After controlling for the other measures, PBQ-SR remained a significant predictor of PTSD symptom severity as assessed by both measures (CAPS: $\beta=.232 ; 95 \%$-CI: $.025-.439 ; \mathrm{t}=2.2 ; \mathrm{p}=.028$; PCL: $\beta=.181$; 95\%-CI: .079-.283; $\mathrm{t}=3.5 ; \mathrm{p}=.001)$.

\section{Cut-off score}

The relation between PTSD-risk status (CAPS score $\geq 45$; whole sample: $4.8 \%$, no prior deployment: $4 \%$ ) and the PBQ total score was also examined using receiver operating characteristic (ROC) curves. Marines with a prior deployment were excluded from the analysis. The area under the curve was .85, which indicates that the PBQ is quite accurate in identifying PTSD-risk positive cases. The ROC diagram suggested a cut-off of 12 points (sensitivity $75.0 \%$, specificity $85.6 \%$ ) as the most appropriate one for screening purposes. In a direct univariate logistic regression, participants with a PBQ-SR total score above 12 had a 17.9 odds ratio of PTSD-risk group affiliation $(B=2.88 ; S E=.59 ;$ Wald $=23.5 ; d f=1$; Sig. <.001; $\operatorname{Exp}(B)=17.9)$. Also after controlling for BDI, BAI, WHODAS and PANAS-N scores in a 
stepwise multiple linear regression model, a PBQ-SR score above 12 was the only significant predictor of affiliation in the PTSD-risk group (full model: $\chi^{2}=46.2$, $\mathrm{p}<.001$, variance explained: $11.0-38.3 \%$, PBQ-SR $\geq 12$ : $B=1.76 ; S E=.73 ;$ Wald $=5.9 ; d f=1 ; p=.015 ; \operatorname{Exp}(B)=$ 5.8 ), indicating that the cut-off score selected was able to distinguish between respondents. Using the PBQ-SR cut-off score of 12 points as a dichotomous variable, we compared the two resulting groups with respect to the other psychometric measures. Participants reporting PBQ-SR scores higher than the cut-off showed significantly higher anxiety (BAI: $\mathrm{t}_{(399)}=-5.075, \mathrm{p}<.001$ ), depression (BDI: $\mathrm{t}_{(399)}=-5.840, \mathrm{p}<.001$ ) and negative affect (PANAS-N: $\left.\mathrm{t}_{(399)}=-6.117, \mathrm{p}<.001\right)$ scores, lower general health scores (WHODAS: $\mathrm{t}_{(399)}=-4.171, \mathrm{p}<.001$ ) and a greater increase of PTSD symptoms after deployment (CAPS-Change: $\mathrm{t}_{(395)}=-2.232, \mathrm{p}=.029 ; \quad$ PCLChange: $\left.\mathrm{t}_{(393)}=-2.381, \mathrm{p}=.020\right)$ than the control group.

\section{Discussion}

This study validates a new instrument for the assessment of peritraumatic symptoms. To our knowledge, PBQ-SR is the first instrument specifically designed to measure several components of combat-related peritraumatic stress. The questionnaire was assessed using retrospective data on 688 Marine infantry service members with respect to the most stressful event during their last deployment. PBQ-SR demonstrated satisfactory psychometric properties with good internal consistency and discriminant validity as to PANAS-Positive Score. Descriptive analysis of each item, inter-item correlation and Cronbach's $\alpha$ stability after item deletion indicate that all 15 items of the questionnaire could be retained. The statistically significant positive correlation between both the PBQ-SR total score and all of its 15 items to the PDEQ confirms the ability of PBQ-SR to reliably assess peritraumatic reactions as a general construct.

Consistent with prior results research [46], there was a significant positive correlation between the PBQ-SR total score and measures of general anxiety, depression, negative affect and lower general health after deployment. PBQ-SR also showed high concurrent validity with respect to posttraumatic symptoms after deployment and their changes over time. PTSD severity strongly correlated not only with PBQ-SR total scores and the two subscales, but also with most of the fifteen individual PBQ-SR items. In order to compare the concurrent psychometric properties of PBQ-SR to PDEQ, we recalculated all correlations with respect to PDEQ (cf. Table 3). Our results suggest similar psychometric properties, while the PBQ-SR shows slightly better concurrent validity to almost every other measure assessed (cf. Table 3).

Linear and logistic regressions have shown that PBQSR total score remained a significant predictive factor of
PTSD symptom severity, even after controlling for depression, general anxiety, negative affect and general health. Our results suggest a PBQ-SR cut-off score of 12 points for screening purposes. This score has been shown to correctly classify respondents at risk for PTSD even after controlling for other psychopathologies. In addition, participants exceeding this cut-off score also showed significantly higher anxiety, depression and negative affect scores, lower general health scores and a greater increase of PTSD symptoms after deployment when compared to the control group.

As literature suggests that peritraumatic symptoms partly rely on pre-existing factors, such as trait dissociation and may be an important risk factor for PTSD development and resilience [24,72,73], we also investigated the correlation between peritraumatic symptoms (PBQ$\mathrm{SR})$, trait dissociation assessed by the DES and posttraumatic symptoms (CAPS). Our results showed a statistically significant correlation between all three scores and confirm prior findings. However, even though the DES total score also correlated significantly with the CAPS total score $(\mathrm{r}=.188, \mathrm{n}=394, \mathrm{p}<.001)$, the close correlation of PBQ-SR to the CAPS total score remained significant even after controlling for trait dissociation $(\mathrm{r}=.370, \mathrm{n}=393, \mathrm{p}<.001)$.

A principal component analysis suggested the existence of two underlying factors: physical/dissociative (PAS) and perceptive/emotional (EDS) aspects of peritraumatic stress reaction. Both factors have demonstrated satisfactory convergent validity to PTSD specific measures and significant concurrent validity correlations to other measures such as general anxiety, depression, negative affect and general health (cf. Tables 2 and 3). At present, the two pre-existing scales assessing peritraumatic reactions (PDEQ and PDI) seem to each focus separately on different dimensions of peritraumatic symptoms. PDEQ's underlying structure is shown to reflect more dissociative symptoms such as altered awareness and derealization (reflecting the PAS), while PDI focuses more on emotional peritraumatic distress symptoms (reflecting the EDS). Hence, our results suggest that PBQ-SR is a new scale that may have incremental validity by unifying and assessing the two major underlying peritraumatic symptom dimensions, which would otherwise require the administration of both PDEQ and the PDI. Assessing both dimensions also affirms the clinical relevancy of PBQ-SR and we therefore support the use of both subscales in clinical practice. The separate use of EDS and PAS could, however, be considered in psychiatric research.

In summary, our study replicates and extends the findings of other studies reporting peritraumatic dissociation to be a robust correlate of PTSD symptoms in adults. Our findings suggest that peritraumatic symptoms as measured by the PBQ may be useful indices of risk and need for early intervention for PTSD in service members 
deployed to combat zones, should, however, be prospectively validated through immediate peritraumatic assessment through in-theater administration of the PBQ-SR in the future.

\section{Limitations and strengths}

Because the content development focused on the behavioral indicators of the phenomenology of service members under great strain in a war-zone, the PBQ stands out as a peritraumatic index uniquely suitable for military members. The PBQ is a questionnaire that is easy to administer and score due to its simple rating and scoring instructions and clearly specified areas of evaluation. The 5-pointLikert scale structure promotes the comparability of our results to prior studies using already existing scales. Concerning the psychometric properties of the PBQ-SR, excluding Marines with prior deployments from the predictive analyses has contributed to the reduction of bias risk due to prior stressors, while the use of the traumaspecific CAPS score likely contributed to a higher specific predictive power of our results. The size, as well as the homogeneity of our assessed sample (Marine, infantry) in terms of gender, age and kind of exposure type is a specific feature and further strength of our study, compared to validation studies designed for other scales. This may be an advantage for military-use of the questionnaire, but may limit its generalizability to other populations. In addition, as the optimal cutoff score was empirically established in our study, cross-validation in an independent sample appears necessary. Further limitations also include the lack of assessment of prior traumatic life events or childhood trauma, combat exposure level and test-retest variability of the measure. In addition, we evaluated the PBQSR on male Marine Corps infantry units who deployed to Afghanistan in a period of time that was relatively quiescent. It is an empirical question whether these results would be generalizable to more highly exposed troops, in other branches of service, and with women. However, the most significant limitation of the study is the retrospective, self-report assessment of peritraumatic symptoms, which precludes a conclusion on predictive validity of the PBQ-SR. Retrospective assessment of symptoms may also lead to distortion of recollections or bias due to current symptoms [74] and subjective assessment of combatrelated symptoms could introduce bias and distortions related to cognitive barriers (i.e. fear of stigma, warrior ethos, criticism, fear of removal from unit, etc.) and adaptive denial coping mechanisms of Service Members [2,75]. Despite those concerns, our results suggest good reliability, validity and applicability of the PBQ-SR.

\section{Conclusion}

The PBQ-SR is a reliable and valid new instrument for globally assessing different underlying dimensions of combat-related peritraumatic symptoms in active duty Service Members and demonstrates high correlation to various PTSD-specific, as well as related symptoms. The PBQ-SR may contribute to more accurate and earlier identification of individuals at high risk for developing combat-related acute and posttraumatic stress symptoms, allowing for further monitoring, coping support or immediate evidence-based treatment. The ability of the PBQ-SR to serve as a standard self-rated questionnaire with incremental validity in military clinical practice and predictive validity towards PTSD development, should, however, be prospectively validated through immediate, in-theater peritraumatic assessment in future studies.

The opinions and assertions contained herein are the private views of the authors, and do not necessarily reflect the official positions or policies of the Department of Defense, the Department of the Navy, or the Department of Veterans Affairs.

\section{Additional file}

Additional file 1: The Peritraumatic Behavior Questionnaire - Self Report (PBQ-SR).

\section{Competing interests}

All authors declare that they have no financial or non-financial competing interests.

\section{Authors' contributions}

AA carried out all statistical analyses and contributed to the interpretation of data and drafting of the manuscript. WPN and DGB conceived of the study and have made substantial contributions to coordination and design. SN and KAY have been involved in drafting the manuscript and revising it critically for important intellectual content. AG, BTL, JBL and DGB contributed to the interpretation of data and have been involved in revising the manuscript critically for important intellectual content. HJ has made substantial contributions to acquisition of data. All authors have given final approval of the version to be published.

\section{Acknowledgements}

We would like to acknowledge CAPT. Brian Schumacher who served medical monitor, as well as the Navy Corpsmen at Camp Pendleton who participated in the PBQ development focus group. The "Validation of the Peritraumatic Behavior Questionnaire" study was funded through Congressionally Directed Medical Research Programs small (pilot) project mechanism (Award No.: Contract W81XWH-10-1-0693) (DGB). The linked MRS study is funded by VA HSR\&D (Grant No.: RDIS 0024), the Marine Corps and Navy BUMED. We would also like to thank Amela Ahmetovic, Nilima Biswas, William H. Black, Mahalah R. Buell, Teresa Carper, Andrew De La Rosa, Benjamin Dickstein, Caitlin Fernandes, Susan Fesperman, David Fink, Summer Fitzgerald, Steven Gerard, Gali Goldwaser, Patricia Gorman, Jorge A. Gutierrez, John A. Hall, Jr, Christian J. Hansen, Laura Harder, Pia Heppner, Alexandra Kelada, Christopher L. Lehnig, Jennifer Lemmer, Morgan LeSuer-Mandernack, Manjula Mahata, Adam X. Maihofer, Theodore Morrison, Arame Motazedi, Elin Olsson, Ines Pandzic, Anjana H. Patel, Dhaval H. Patel, Sejal Patel, Shetal M. Patel, Taylor Perin-Kash, James O.E. Pittman, Stephanie Raducha, Brenda Thomas, Elisa Tsan, Maria Anna Valencerina, Chelsea Wallace, Kuixing Zhang, and the many intermittent on-site MRS clinician-interviewers and data collection staff.

\section{Author details}

"Veterans Affairs Center of Excellence for Stress and Mental Health, VA San Diego, CA, USA. ${ }^{2}$ Department of Psychiatry and Psychotherapy, University Medical Center Hamburg-Eppendorf, Hamburg, Germany. ${ }^{3}$ Department of Psychiatry, University of California, San Diego, CA, USA. ${ }^{4}$ VA San Diego 
Healthcare System, San Diego, CA, USA. ${ }^{5}$ Department of Psychiatry and Department of Psychology, Boston University School of Medicine, Boston MA, USA. ${ }^{6}$ National Center for Post Traumatic Stress Disorder, VA Boston Healthcare System, Boston, MA, USA. ${ }^{7}$ Department of Psychiatry, University of California San Diego, 9500 Gilman Drive (0603V), La Jolla, CA 92093-0603V,

Received: 8 October 2012 Accepted: 2 January 2013

Published: 5 January 2013

\section{References}

1. Smith TC, Ryan MA, Wingard DL, Slymen DJ, Sallis JF, Kritz-Silverstein D: New onset and persistent symptoms of post-traumatic stress disorder self reported after deployment and combat exposures: prospective population based US military cohort study. BMJ Clinical research ed 2008, 336(7640):366-371.

2. Hoge CW, Castro CA, Messer SC, McGurk D, Cotting DI, Koffman RL: Combat duty in Iraq and Afghanistan, mental health problems, and barriers to care. N Engl J Med 2004, 351(1):13-22.

3. Lapierre CB, Schwegler AF, Labauve BJ: Posttraumatic stress and depression symptoms in soldiers returning from combat operations in Iraq and Afghanistan. J Trauma Stress 2007, 20(6):933-943.

4. Hellmann J, Heuser I, Kronenberg G: Targeted prevention of posttraumatic stress disorder. Nervenarzt 2010, Epub ahead of print.

5. Grasso D, Boonsiri J, Lipschitz D, Guyer A, Houshyar S, Douglas-Palumberi H, Massey J, Kaufman J: Posttraumatic stress disorder: the missed diagnosis. Child Welfare 2009, 88(4):157-176.

6. Druss BG, Hwang I, Petukhova M, Sampson NA, Wang PS, Kessler RC: Impairment in role functioning in mental and chronic medical disorders in the United States: results from the National Comorbidity Survey Replication. Mol Psychiatry 2009, 14(7):728-737.

7. Bovin MJ, Marx BP: The importance of the peritraumatic experience in defining traumatic stress. Psychol Bull 2011, 137(1):47-67.

8. Ozer EJ, Best SR, Lipsey TL, Weiss DS: Predictors of posttraumatic stress disorder and symptoms in adults: a meta-analysis. Psychol Bull 2003, 129(1):52-73.

9. Lima AA, Fiszman A, Marques-Portella C, Mendlowicz MV, Coutinho ES, Maia DC, Berger W, Rocha-Rego V, Volchan E, Mari JJ, et al: The impact of tonic immobility reaction on the prognosis of posttraumatic stress disorder J Psychiatr Res 2010, 44(4):224-228.

10. Lensvelt-Mulders G, van der Hart O, van Ochten JM, van Son MJ, Steele K, Breeman L: Relations among peritraumatic dissociation and posttraumatic stress: a meta-analysis. Clin Psychol Rev 2008, 28(7):1138-1151.

11. Gershuny BS, Cloitre M, Otto MW: Peritraumatic dissociation and PTSD severity: do event-related fears about death and control mediate their relation? Behav Res Ther 2003, 41(2):157-166

12. Gould NF, McKibben JB, Hall R, Corry NH, Amoyal NA, Mason ST, McCann UD, Fauerbach JA: Peritraumatic heart rate and posttraumatic stress disorder in patients with severe burns. J Clin Psychiatry 2011, 72(4):539-547.

13. Marmar CR, McCaslin SE, Metzler TJ, Best S, Weiss DS, Fagan J, Liberman A, Pole N, Otte C, Yehuda R, et al: Predictors of posttraumatic stress in police and other first responders. Ann N Y Acad Sci 2006, 1071:1-18.

14. McGhee LL, Slater TM, Garza TH, Fowler M, DeSocio PA, Maani CV: The relationship of early pain scores and posttraumatic stress disorder in burned soldiers. J Burn Care Res 2011, 32(1):46-51.

15. Breh DC, Seidler GH: Is peritraumatic dissociation a risk factor for PTSD? J Trauma Dissociation 2007, 8(1):53-69.

16. McNally RJ: Psychological mechanisms in acute response to trauma. Biol Psychiatry 2003, 53(9):779-788.

17. Briere J, Scott C, Weathers F: Peritraumatic and persistent dissociation in the presumed etiology of PTSD. Am J Psychiatry 2005, 162(12):2295-2301

18. Fikretoglu D, Brunet A, Best S, Metzler T, Delucchi K, Weiss DS, Fagan J, Marmar C: The relationship between peritraumatic distress and peritraumatic dissociation: an examination of two competing models. J Nerv Ment Dis 2006, 194(11):853-858.

19. Griffin MG, Resick PA, Mechanic MB: Objective assessment of peritraumatic dissociation: psychophysiological indicators. Am J Psychiatry 1997, 154(8):1081-1088.
20. Gabert-Quillen CA, Fallon W, Delahanty DL: PTSD after traumatic injury: an investigation of the impact of injury severity and peritraumatic moderators. J Health Psychol 2011, 16(4):678-687.

21. Pacella ML, Irish L, Ostrowski SA, Sledjeski E, Ciesla JA, Fallon W, Spoonster E, Delahanty DL: Avoidant coping as a mediator between peritraumatic dissociation and posttraumatic stress disorder symptoms. J Trauma Stress 2011, 24(3):317-325.

22. Eid J, Morgan CA 3rd: Dissociation, hardiness, and performance in military cadets participating in survival training. Mil Med 2006, 171(5):436-442.

23. Morgan CA, Southwick SM, Hazliett G, Dial-Ward M: Baseline dissociation and prospective success in special forces assessment and selection. Psychiatry (Edgmont) 2008, 5(7):53-58.

24. Galatzer-Levy IR, Madan A, Neylan TC, Henn-Haase C, Marmar CR: Peritraumatic and trait dissociation differentiate police officers with resilient versus symptomatic trajectories of posttraumatic stress symptoms. J Trauma Stress 2011, 24(5):557-565.

25. Orr SP, Metzger LJ, Lasko NB, Macklin ML, Peri T, Pitman RK: De novo conditioning in trauma-exposed individuals with and without posttraumatic stress disorder. J Abnorm Psychol 2000, 109(2):290-298.

26. Tiet QQ, Rosen C, Cavella S, Moos RH, Finney JW, Yesavage J: Coping, symptoms, and functioning outcomes of patients with posttraumatic stress disorder. J Trauma Stress 2006, 19(6):799-811.

27. Henckens MJ, Hermans EJ, Pu Z, Joels M, Fernandez G: Stressed memories: how acute stress affects memory formation in humans. J Neurosci 2009, 29(32):10111-10119

28. McCleery JM, Harvey AG: Integration of psychological and biological approaches to trauma memory: implications for pharmacological prevention of PTSD. J Trauma Stress 2004, 17(6):485-496.

29. Zohar J, Juven-Wetzler A, Myers V, Fostick L: Post-traumatic stress disorder: facts and fiction. Curr Opin Psychiatry 2008, 21(1):74-77.

30. Otte C, Neylan TC, Pole N, Metzler T, Best S, Henn-Haase C, Yehuda R, Marmar CR: Association between childhood trauma and catecholamine response to psychological stress in police academy recruits. Biol Psychiatry 2005, 57(1):27-32.

31. Southwick SM, Bremner JD, Rasmusson A, Morgan CA 3rd, Arnsten A, Charney DS: Role of norepinephrine in the pathophysiology and treatment of posttraumatic stress disorder. Biol Psychiatry 1999, 46(9):1192-1204.

32. Pitman RK, Shalev AY, Orr SP: Posttraumatic stress disorder: emotion conditioning and memory. In The New Cognitive Neurosciences. Edited by Corbetta MD, Gazzaniga MS. New York: Plenum Press; 2000:687-700.

33. Krystal JH, Neumeister A: Noradrenergic and serotonergic mechanisms in the neurobiology of posttraumatic stress disorder and resilience. Brain Res 2009, 1293:13-23.

34. Friedman MJ, Pitman RK: New findings on the neurobiology of posttraumatic stress disorder. J Trauma Stress 2007, 20(5):653-655.

35. Heim C, Nemeroff CB: Neurobiology of posttraumatic stress disorder. CNS Spectr 2009, 14(1 Suppl 1):13-24.

36. Milad MR, Pitman RK, Ellis CB, Gold AL, Shin LM, Lasko NB, Zeidan MA, Handwerger K, Orr SP, Rauch SL: Neurobiological basis of failure to recall extinction memory in posttraumatic stress disorder. Biol Psychiatry 2009, 66(12):1075-1082.

37. Bryant RA: Acute stress reactions: can biological responses predict posttraumatic stress disorder? CNS Spectr 2003, 8(9):668-674.

38. Cahill L, Prins B, Weber M, McGaugh JL: Beta-adrenergic activation and memory for emotional events. Nature 1994, 371(6499):702-704.

39. Ehring T, Ehlers A, Cleare AJ, Glucksman E: Do acute psychological and psychobiological responses to trauma predict subsequent symptom severities of PTSD and depression? Psychiatry Res 2008, 161(1):67-75.

40. Birmes P, Brunet A, Carreras D, Ducasse JL, Charlet JP, Lauque D, Sztulman $H$, Schmitt $L$ : The predictive power of peritraumatic dissociation and acute stress symptoms for posttraumatic stress symptoms: a three-month prospective study. Am J Psychiatry 2003, 160(7):1337-1339.

41. Agorastos A, Marmar CR, Otte C: Immediate and early behavioral interventions for the prevention of acute and posttraumatic stress disorder. Curr Opin Psychiatry 2011, 24(6):526-532.

42. Nash WP, Krantz L, Stein N, Westphal R, Litz BT: Comprehensive soldier fitness, battlemind, and the stress continuum model: military organizational approaches to prevention. In Caring for veterans with deployment-related stress disorders. Edited by Ruzek JI, Schnurr PP, Vasterling 
JJ, Friedman MJ. Iraq, Afghanistan, and beyond: American Psychological Association; 2011:193-214.

43. Birmes $P$, Brunet $A$, Benoit M, Defer S, Hatton L, Sztulman H, Schmitt L: Validation of the Peritraumatic Dissociative Experiences Questionnaire self-report version in two samples of French-speaking individuals exposed to trauma. Eur Psychiatry 2005, 20(2):145-151.

44. Brunet A, Weiss DS, Metzler TJ, Best SR, Neylan TC, Rogers C, Fagan J, Marmar CR: The Peritraumatic Distress Inventory: a proposed measure of PTSD criterion A2. Am J Psychiatry 2001, 158(9):1480-1485.

45. Bui E, Brunet A, Allenou C, Camassel C, Raynaud JP, Claudet I, Fries F, Cahuzac JP, Grandjean H, Schmitt L, et al: Peritraumatic reactions and posttraumatic stress symptoms in school-aged children victims of road traffic accident. Gen Hosp Psychiatry 2010, 32(3):330-333.

46. Marmar CR, Metzler TJ, Otte C: The Peritraumatic Dissociative Experience Questionnaire. In Assessing Psychological Trauma and PTSD: A Handbook for Practitioners. Edited by Wilson JP, Keane TM. New York, NY: Guilford Press; 2004:144-167.

47. Nishi D, Matsuoka Y, Yonemoto N, Noguchi H, Kim Y, Kanba S: Peritraumatic Distress Inventory as a predictor of post-traumatic stress disorder after a severe motor vehicle accident. Psychiatry Clin Neurosci 2010, 64(2):149-156.

48. Baker DG, Nash WP, Litz BT, Geyer MA, Risbrough VB, Nievergelt CM, O'Connor DT, Larson GE, Schork NJ, Vasterling JJ, et al: Predictors of risk and resilience for posttraumatic stress disorder among ground combat marines: methods of the marine resiliency study. Prev Chronic Dis 2012, 9:E97.

49. Vogt DS, King DW, King LA: Focus groups in psychological assessment: enhancing content validity by consulting members of the target population. Psychol Assess 2004, 16(3):231-243.

50. Haynes SN, Richard DC, Kubany ES: Content validity in psychological assessment: a functional approach to concepts and methods. Psychol Assess 1995, 7(3):238-247.

51. Helmer O: Looking forward: A guide to future research. Beverly Hills, CA: Sage; 1983.

52. Nijenhuis ER, Spinhoven P, Van Dyck R, Van der Hart O, Vanderlinden J: The development and psychometric characteristics of the Somatoform Dissociation Questionnaire (SDQ-20). J Nerv Ment Dis 1996 184(11):688-694

53. Nijenhuis ER, Spinhoven $P$, van Dyck R, van der Hart O, Vanderlinden J: Degree of somatoform and psychological dissociation in dissociative disorder is correlated with reported trauma. J Trauma Stress 1998, 11(4):711-730

54. Marmar CR, Weiss DS, Metzler TJ: The Peritraumatic Dissociative Experiences Questionnaire. In Assessing Psychological Trauma and PTSD. Edited by Wilson JP, Keane TM. New York, NY: Guilford Press; 1997:412-428.

55. Bremner JD, Krystal JH, Putnam FW, Southwick SM, Marmar C, Charney DS, Mazure CM: Measurement of dissociative states with the ClinicianAdministered Dissociative States Scale (CADSS). J Trauma Stress 1998, 11(1):125-136

56. Bruner VE, Woll P: The battle within: understanding the physiology of war-zone stress experience. Soc Work Health Care 2011, 50(1):19-33.

57. Nash WP, Steenkamp M, Conoscenti L, Litz BT: The stress continuum model: a military organizational approach to resilience and recovery. In Resilience and Mental Health: Challenges Across the Lifespan. Edited by Southwick SM, Litz BT, Charney D, Friedman MJ. New York: Cambridge University Press; 2011.

58. Dubester KA, Braun BG: Psychometric properties of the Dissociative Experiences Scale. J Nerv Ment Dis 1995, 183(4):231-235.

59. Wright DB, Loftus EF: Measuring dissociation: comparison of alternative forms of the dissociative experiences scale. Am J Psychol 1999, 112(4):497-519.

60. Blanchard EB, Jones-Alexander J, Buckley TC, Forneris CA: Psychometric properties of the PTSD Checklist (PCL). Behav Res Ther 1996, 34(8):669-673.

61. Wilkins KC, Lang AJ, Norman SB: Synthesis of the psychometric properties of the PTSD checklist (PCL) military, civilian, and specific versions. Depress Anxiety 2011, 28(7):596-606.

62. Blake DD, Weathers FW, Nagy LM, Kaloupek DG, Gusman FD, Charney DS, Keane TM: The development of a Clinician-Administered PTSD Scale. J Trauma Stress 1995, 8(1):75-90.

63. Weathers FW, Litz BT: Psychometric properties of the ClinicianAdministered PTSD Scale, CAPS-1. PTSD Research Quarterly 1994, 5:2-6.
64. Weathers FW, Ruscio AM, Keane TM: Psychometric properties of nine scoring rules for the Clinician-Administered Posttraumatic Stress Disorder Scale. Psychol Assess 1999, 11(2):124-133.

65. Watson D, Clark LA, Tellegen A: Development and validation of brief measures of positive and negative affect: the PANAS scales. J Pers Soc Psychol 1988, 54(6):1063-1070.

66. Crawford JR, Henry JD: The positive and negative affect schedule (PANAS): construct validity, measurement properties and normative data in a large non-clinical sample. Br J Clin Psychol 2004, 43(Pt 3):245-265.

67. Beck AT, Ward CH, Mendelson M, Mock J, Erbaugh J: An inventory for measuring depression. Arch Gen Psychiatry 1961, 4:561-571.

68. Beck AT, Steer RA, Garbin MG: Psychometric properties of the Beck depression inventory: twenty-five years of evaluation. Clin Psychol Rev 1998, 8:77-100.

69. Beck AT, Epstein N, Brown G, Steer RA: An inventory for measuring clinical anxiety: psychometric properties. J Consult Clin Psychol 1988, 56(6):893-897.

70. Gandek B, Ware JE, Aaronson NK, Apolone G, Bjorner JB, Brazier JE, Bullinger $M$, Kaasa S, Leplege A, Prieto $L$, et al: Cross-validation of item selection and scoring for the SF-12 Health Survey in nine countries: results from the IQOLA Project. International Quality of Life Assessment. J Clin Epidemiol 1998, 51(11):1171-1178.

71. World Health Organization: Measuring Health and Disability: Manual for WHO Disability Assessment Schedule - WHODAS 2.0. Geneva: WHO; 2010.

72. Inslicht SS, McCaslin SE, Metzler TJ, Henn-Haase C, Hart SL, Maguen S, Neylan TC, Marmar CR: Family psychiatric history, peritraumatic reactivity, and posttraumatic stress symptoms: a prospective study of police. J Psychiatr Res 2010, 44(1):22-31.

73. McCaslin SE, Inslicht SS, Metzler TJ, Henn-Haase C, Maguen S, Neylan TC, Choucroun G, Marmar CR: Trait dissociation predicts posttraumatic stress disorder symptoms in a prospective study of urban police officers. J NerV Ment Dis 2008, 196(12):912-918

74. Southwick SM, Morgan A, Nicolaou AL, Charney DS: Consistency of memory for combat-related traumatic events in veterans of operation desert storm. Am J Psychiat 1997, 154(2):173-177.

75. Nash WP: Combat/operational stress adaptations and injuries. In Combat Stress Injury Theory, Research, and Management. Edited by Figley CR, Nash WP. New York, NY: Routledge Press; 2007.

doi:10.1186/1471-244X-13-9

Cite this article as: Agorastos et al:: The Peritraumatic Behavior

Questionnaire: development and initial validation of a new measure for combat-related peritraumatic reactions. BMC Psychiatry 2013 13:9.

\section{Submit your next manuscript to BioMed Central and take full advantage of:}

- Convenient online submission

- Thorough peer review

- No space constraints or color figure charges

- Immediate publication on acceptance

- Inclusion in PubMed, CAS, Scopus and Google Scholar

- Research which is freely available for redistribution 